\section{Translational opportunities for targeting the Th17 axis in acute graft-vs.-host disease}

\author{
F Malard ${ }^{1,2,3,4}$, B Gaugler ${ }^{1,2}$, B Lamarthee Land M Mohty $^{1,2,3}$
}

Allogeneic stem cell transplantation (allo-SCT) is a curative therapy for different life-threatening malignant and nonmalignant hematologic disorders. Acute graft-vs.-host disease (aGVHD) and particularly gastrointestinal aGVHD remains a major source of morbidity and mortality following allo-SCT, which limits the use of this treatment in a broader spectrum of patients. Better understanding of aGVHD pathophysiology is indispensable to identify new therapeutic targets for aGVHD prevention and therapy. Growing amount of data suggest a role for T helper (Th)17 cells in aGVHD pathophysiology. In this review, we will discuss the current knowledge in this area in animal models and in humans. We will then describe new potential treatments for aGVHD along the Th17 axis.

\section{INTRODUCTION}

Allogeneic stem cell transplantation (allo-SCT) is a curative therapy for different life-threatening hematologic malignancies. The therapeutic efficacy of allo-SCT relies on the combination of the cytoreductive effect of the conditioning chemotherapy and/or radiotherapy and of the graft-vs.-tumor effect mediated by the donor's immunocompetent cells $(\mathrm{CD} 8+$ and $\mathrm{CD} 4+\mathrm{T}$ cells, natural killer cells and dendritic cells). However, the beneficial effect of graftvs.-tumor effect is counterbalanced by the immunological recognition and destruction of host tissues by the donor's immune effectors, termed graft-vs.-host disease (GVHD). GVHD remains a major source of morbidity and mortality following allo-SCT. Gooley et al. ${ }^{1}$ recently reported a substantial reduction in death related to allo-SCT and an increased long-term survival. Similarly, we reported ${ }^{2}$ a significant reduction of non-relapse mortality significantly and improvement of overall survival in the 2001-2010 period, compared with 1983-2000 period, while the incidence of acute GVHD (aGVHD) remained stable, and the incidence of extensive chronic GVHD increased, during the same period. ${ }^{2}$ Therefore, it is essential to improve GVHD management.

Consequently, there have been several attempts to develop biological biomarkers to predict GVHD onset or responsiveness to treatment. ${ }^{3,4}$ This would allow a more stringent monitoring and intensified prophylaxis or curative treatment of GVHD in those patients. Furthermore, recent progress in medical imaging test and endoscopic techniques, such as contrast-enhanced ultrasound or probe-based confocal endomicroscopy, may allow an earlier and more specific diagnosis of GVHD, ${ }^{5,6}$ particularly for gastrointestinal aGVHD (reviewed in Malard and Mohty ${ }^{7}$ ). Finally, identification of new therapeutic targets and development of new immunosuppressive therapy are indispensables to further improve GVHD management.

The pathophysiology of aGVHD is a multistep process. ${ }^{8,9}$ In the first step, the conditioning regimen (chemotherapy and/or total body irradiation) leads to host tissue damage, release of proinflammatory cytokines, and increased expression of major and minor histocompatibility antigens and costimulatory molecules on host antigenpresenting cells. In the second step, donor-derived $\mathrm{CD} 4+$ and $\mathrm{CD} 8+\mathrm{T}$ cells are activated by host antigen-presenting cell and migrate into GVHD target tissues (gastrointestinal tract, skin, and liver). In the third step, cellular mediators (such as cytotoxic T lymphocytes, activated macrophages, and natural killer cells) and inflammatory cytokines act synergistically to enhance

\footnotetext{
${ }^{1}$ Université Pierre et Marie Curie, Paris, France. ${ }^{2}$ Centre de recherche Saint-Antoine, INSERM, UMRs 938, Paris, France. ${ }^{3}$ Service d'Hématologie Clinique et de Thérapie Cellulaire, Hôpital Saint Antoine, APHP, Paris, France and ${ }^{4}$ INSERM, UMR 1064-Center for Research in Transplantation and Immunology, Nantes, F44093 France. Correspondence: F Malard or M Mohty (florent.malard@univ-nantes.fr or Mohamad.mohty@inserm.fr)
} 
target tissue destruction. ${ }^{8,9}$ For a long time, we considered that a particular subset of CD4 $+\mathrm{T}$ helper (Th) cells, Th1 cells, was at play during the effector phase of aGVHD. ${ }^{10,11}$ However, the identification of a new Th subset, Th17 cells, raised the question of their role in aGVHD. Therefore, in this review we will discuss the most recent data on the contribution of these Th17 cells and Th17-related cytokines in aGVHD pathophysiology.

\section{Th17 CELLS}

\section{Th17 cells differentiation}

In 2005 , two seminal studies ${ }^{12,13}$ showed in a mouse model that the development of Th17 cells from naive precursors was independent of Th1- and Th2-specific transcription factors (Tbet and Gata-3), leading to the establishment of the Th17 lineage as independent and distinct from the Th1 and Th2 lineages. ${ }^{12,13}$ Another group reported that mouse Th17 cells uniquely expressed a transcription factor termed retinoid acid-related orphan receptor (ROR) $\gamma \mathrm{t}$ (encoded by the gene Rorc)..$^{14}$

Besides ROR $\gamma$ t, STAT3 is the second transcription factor required for Th17 cells differentiation. STAT3 has pleiotropic functions as a transcriptional activator for Rorc, IL-17, IL-17F, IL$23 R$, and others genes implied in Th17 cell differentiation or survival in murine models. ${ }^{15}$ Several cytokines have a role in Th17 cell differentiation, upon the control of the ROR $\gamma \mathrm{t}$ and STAT3 transcription factors.

In murine models, interleukin (IL)-6 has an essential role in this process by activating STAT3, ${ }^{16}$ which directly drives the transcription of Th17 lineage specific genes ${ }^{15}$ and suppresses transforming growth factor (TGF) $\beta$-induced forkhead box P3 (FOXP3) expression, thereby inhibiting regulatory T-cell (Treg) development. ${ }^{17}$ IL-6 also induces the expression of IL-1R 1 by mouse Th17 cells. ${ }^{18}$ IL-1 $\beta$, through its receptor IL$1 \mathrm{R} 1$, promotes the transcription factor interferon-regulatory factor 4 , which reinforces the expression of $\mathrm{ROR} \gamma \mathrm{t}$, and enhances Th17 proliferation in experimental models. ${ }^{18}$ Therefore, these data suggest that if IL-6 directly drives the differentiation of Th17 cells, IL-1 $\beta$ enhances the expansion of these cells. Alternatively, IL-21 selectively induces the phosphorylation of STAT3 and replacement of IL-6 with IL-21 in combination with TGF $\beta$, interferon $\gamma$ (IFN $\gamma$ ), and IL-4, was very effective to induce high level of IL-17-producing cells in a mouse model. ${ }^{19}$ Furthermore, IL-21 is also produced by Th17 cells, promoting self-maintenance of Th17 cells. ${ }^{20}$ Regarding TGF $\beta$, although the data suggest that TGF $\beta$ is required for Th17 cells differentiation in mouse models, ${ }^{21,22}$ it probably does not act as a direct Th17 cell-inducing factor, but rather allows Th17 cells differentiation indirectly by suppressing alternative cell fates. $^{23,24}$

In humans, although the role of IL-6 and IL-1 $\beta$ is well established on in vitro cultures of human $\mathrm{T}$ cells, ${ }^{25-27}$ the contribution of TGF $\beta$ to Th17 cells differentiation remains a matter of debate. Although some groups have shown that TGF $\beta$ is necessary for in vitro Th17 cell differentiation, ${ }^{28,29}$ others found that Th17 cells could differentiate without TGF $\beta$, upon stimulation with a cocktail of IL-6, IL- $1 \beta$, and IL-23. ${ }^{25-27}$ However, these are in vitro data, and it is difficult to draw definitive conclusion regarding the role of TGF $\beta$ for Th17 cells differentiation under in vivo inflammatory conditions in human. Besides, IL-21, produced by a number of T cells and the NK cell subset, is also involved in human Th17 cells differentiation via STAT3 signaling. ${ }^{29}$

IL-23 is another key cytokine for Th17 cells commitment. Therefore, despite the combination of IL- 6 and TGF $\beta$ being sufficient to drive Th17 cells differentiation, the cells generate by this combination fail to induce pathogenicity in mouse models. ${ }^{30}$ However, IL-6 and TGF $\beta$ induce IL-23R expression, ${ }^{16}$ and subsequent exposure to IL-23 stabilizes the phenotype ${ }^{31}$ and expands the pathogenicity of Th17 cells. ${ }^{27,30,32}$

\section{Th17 cell plasticity}

Despite initial thoughts that $\mathrm{CD} 4+$ naive $\mathrm{T}$ cells differentiate into terminal phenotypes in a rigid process, it is now quite well-accepted that, depending on the cytokine milieu, certain Th subset can adopt a mixed phenotype or switch entirely to the transcription and cytokine profile of another lineage. Given that TGF $\beta$ suppresses Th1 and Th2 differentiation in mouse, ${ }^{23,24}$ both Th17 and induced Treg (iTreg) development is favored in its presence. Therefore, after T cell receptor (TCR) engagement, $\mathrm{CD} 4+$ $\mathrm{T}$ cell differentiation into Th17 or iTreg in the presence of TGF $\beta$ will depend on the cytokine environment: in the absence of proinflammatory signals, naive $\mathrm{T}$ cells will differentiate into iTregs, whereas IL-6 will promote Th17 cell development both in mouse models and in vivo in human. ${ }^{23,24,33}$ The presence of all-trans retinoid acid in the microenvironment seems to inhibit Th17 and promote iTreg development in mouse, in part, at least, by antagonizing the effect of IL-6. ${ }^{34-37}$ Therefore, Yang et al. ${ }^{38}$ demonstrated in a mouse model that upon IL-6 stimulation, both natural Treg and iTreg repress Foxp3 and produce IL-17, suggesting that fully differentiated Treg could be converted into Th17-like cells. In human, Koenen et al. have shown in vivo that circulating Foxp3 + Treg can differentiate into IL-17-producing cells $\mathrm{ROR} \gamma \mathrm{t}+$, given that antigen-presenting cell, in particular monocyte, and the cytokine IL-2 or IL-15 are present. ${ }^{39}$ Of note, this differentiation process was enhanced by exogenous IL-1 $\beta$, IL-23, and IL-21, whereas IL- 6 or TGF $\beta$ did not affect the emergence of IL-17-producing cells. ${ }^{39}$ The in vivo existence of hybrid Treg/Th17 cells in human has been established in inflamed intestinal mucosa of patients with Crohn disease. ${ }^{40}$ These cells express Foxp3 and ROR $\gamma \mathrm{t}$ and produce IL-17, however, unlike conventional Th17 cells, they functionally retain their suppressive activity in vitro. ${ }^{40}$ A similar TCR $\beta$ chain variable region between Treg/Th17 and Treg cells suggest that those Treg/Th17 cells arise from Treg cell when exposed to the inflammatory signals present in inflamed Crohn disease tissue. ${ }^{40}$ Similarly, Voo et al. ${ }^{41}$ reported that human peripheral blood and lymphoid tissue contain a subpopulation of Foxp3+ Treg cells that coexpress ROR $\gamma t$ and 
have the capacity to produce IL-17 upon activation. In contrast, the conversion of Th17 cells into Treg has not been reported so far.

Similarly, the Th1 and the Th17 pathways share a common point: a critical event in the late development of both pathways is the induction of a receptor for an IL-12 cytokine family member: IL-12 for Th1 and IL-23 for Th17. These receptors share a common subunit, the IL-12R $\beta 1$, associated with the IL-12R $\beta 2$ to form the IL-12 receptor, ${ }^{42}$ and with the IL-23R to form the IL23 receptor. Similarly to the IL-23R upregulation during Th17 cell differentiation, ${ }^{16} \mathrm{IL}-12 \mathrm{R} \beta 2$ is upregulated during Th1 cell differentiation. ${ }^{43}$ However, during their differentiation, Th17 cells also weakly express the IL-12R $\beta 1$. Therefore, both in vivo mouse data and in vitro human studies have shown that depending on the balance between the cytokines present in the milieu, IL-12 can induce the conversion of Th17 cells into IFN $\gamma$ producing Th1-like cells. ${ }^{44,45}$ These cells maintain their IL-17 memory upon subsequent culture. ${ }^{44,45}$ Finally, in vivo existence in Crohn disease patients of a Th1/Th17 hybrid subset that arises from the modulation of Th17 cells by IL-12 has been established. ${ }^{45}$

Regarding Th2 subset, in vitro culture of mouse T cells under mixed Th1 and Th2 conditions resulted in a continuum of mixed phenotypes with subpopulations of cells expressing only IFN $\gamma$, only IL-4 or both cytokines, correlating with the expression level of Tbet and Gata-3. ${ }^{46}$ The in vivo existence of Th1/Th2 hybrid subset has been confirmed in a mouse model; during infection with Heligmosomoides polygyrus, a parasite that triggers a strong Th2 response, Th1/Th2 hybrid cells, that express simultaneously Tbet and Gata-3, have been observed. ${ }^{47}$ Hegazy et al. demonstrated in a murine model that injection of Th1 cell-promoting lymphocytic choriomeningitis virus reprogrammed otherwise stably committed Gata-3 + Th2 cells to adopt a Gata- $3+$ Tbet + and IL- $4+$ IFN $\gamma+$ "Th1/Th2" phenotype that was maintained in vivo for months. ${ }^{48}$ Moreover, Th2 cell reprogramming into hybrid Th1/Th2 subset required TCR stimulation and concerted type 1 and 2 IFN and IL-12 signals. ${ }^{48}$ Finally, since the presence of IL-4, during in vitro naive T-cell activation, inhibits ROR $\gamma \mathrm{t}$ expression and IL-17 production, hybrid Th2/Th17 were thought not to exist. However, Califano et al. ${ }^{49}$ have recently shown in a mouse model of autoimmune encephalomyelitis that Th17 deficient in the transcription factor BCL11B upregulate the Th2-associated proteins Gata3 and IL-4 without decreasing ROR $\gamma \mathrm{t}$ and IL-17 level. So far, no data has been reported on the existence of Th1/Th2 or Th2/Th17 hybrid subset in human.

\section{Th17 role}

Th17 cells produce several cytokines, which are not typically produced by Th1 and Th2 cells. These cytokines include IL-17A, IL-17F, IL-17A/F, IL-21, IL-22, granulocyte macrophage colony-stimulating factor or human IL-26, and many other factors. ${ }^{50}$ Th17 are usually present in the lamina propria of the small intestine $^{14}$ and can be rapidly induced in other mucosal sites during infection. ${ }^{51-53}$ Therefore, Th17 cells and Th17-related cytokine contribute to the host defense against a wide variety of pathogens, predominantly extracellular bacteria and fungal pathogens, in the epithelial barrier of gut, skin and lung. ${ }^{50,54}$ Thus, once released, IL-17 and IL-22 act synergistically to enhance mucosal site defences by the production of antimicrobial peptide such as $\beta$ defensine- 2 or S100 proteins. ${ }^{55}$

Finally, Th17 responses also contribute to the pathogenesis of some diseases. ${ }^{50}$ Therefore, their contribution to the pathophysiology of several autoimmune and autoinflammatory diseases affecting epithelial barrier, such as psoriasis or inflammatory bowel disease, is well established. ${ }^{50}$ Given that aGVHD involves mostly the gastrointestinal tract, the skin, and the liver, which contain epithelial barrier, Th17 contribution has been explored in aGVHD pathophysiology.

\section{Th17 CELLS IN aGVHD}

Studies in mouse models of aGVHD The contribution of Th17 cells in aGVHD pathophysiology has been demonstrated in several mouse models. Lu et al. found that phosphorylation of STAT3, a transcriptional factor involved in Th17 cell differentiation, ${ }^{15}$ was important during $\mathrm{T}$ cells alloactivation during aGVHD and that interference with STAT3 phosphorylation can inhibit T-cell activation and proliferation in vitro and aGVHD in vivo, suggesting a role for Th17 cells in aGVHD. ${ }^{56}$ Thereafter, Carlson et al. and Iclozan et al. have shown that adoptive transfer of in vitro differentiated Th17 cells mediate IL-17-dependent lethal aGVHD with severe tissue lesions. ${ }^{57,58}$ In a mouse model of aGVHD using IL-17-/donor $\mathrm{CD} 4+\mathrm{T}$ cells, Kappel et al. ${ }^{59}$ found that aGVHD development was significantly delayed compared with recipients of wild-type $\mathrm{CD} 4+\mathrm{T}$ cells, although the overall GVHD mortality remained unaffected. They concluded that despite Il-17 being dispensable for aGVHD, it contributes to its early development. ${ }^{59}$ In contrast, Yi et al. ${ }^{60}$ reported on a similar model that transplantation of IL-17 - / - donor CD4 + $\mathrm{T}$ cells induced exacerbated aGVHD compared with wild-type CD4 + T cells, while administration of recombinant IL-17 and neutralizing IFN $\gamma$ to the recipients given IL-17 - / - donor cells ameliorated aGVHD. Their conclusion was that donor Th17 cells ameliorate aGVHD through downregulation of Th1 cell differentiation. ${ }^{60}$ Nevertheless, given the plasticity between Th17 and Th1 cells, ${ }^{44,45}$ this result could be explained by an enhanced differentiation of Th1 cells in recipients given IL-17-/ donor cells, and does not contradict a pathological role for Th17 cells in aGVHD. Therefore, Gartlan et al. recently identified a population of inflammatory CD8 + cytotoxic $\mathrm{T}(\mathrm{Tc})$ 17 cells (iTc17) that develops rapidly after allo-SCT and contribute to GVHD but failed to maintain lineage fidelity. ${ }^{61}$

Yi et al. ${ }^{62}$ also showed that administration of donor $\mathrm{CD} 4+\mathrm{T}$ cells depleted for both IFN $\gamma$ and IL-4 (a Th2-related cytokine) resulted in augmented Th17 differentiation, and preferential, though not exclusive, aGVHD damage to the skin. Fulton et al. ${ }^{63}$ have shown, in a major mismatch murine model, that 
deletion of Rorc in both CD4+ and $\mathrm{CD} 8+$ donor $\mathrm{T}$ cells attenuated aGVHD and decreased tissue pathology in the colon, liver, and lung. Hill et al. have shown that use of granulocyte colony-stimulating factor for stem cell mobilization invoke Th17 responses rather than Th1/Th2 differentiation. ${ }^{64}$ Therefore, while transplantation of granulocyte colony-stimulating factormobilized graft from wild-type or IL-17A - / - B6 donors resulted in identical GVHD outcome in models of aGVHD, transplantation of graft from IL-17A - / - BALB/c donors resulted in attenuated GVHD, suggesting a role for IL-17A in GVHD. However, in both recipients of $\mathrm{B} 6$ and $\mathrm{BALB} / \mathrm{C}$ donor grafts, IL-17A promoted cutaneous GVHD with increased levels of both inflammation and fibrosis in the skin of wild-type grafts, suggesting that use of granulocyte colony-stimulating factormobilized grafts promoted sclerodermatous chronic GVHD. In a more relevant haploidentical murine transplantation model, Rorc- / - CD4 + T cells alone diminished the severity and the lethality of aGVHD. ${ }^{63}$ Finally, Uryu et al. ${ }^{65}$ recently reported that $\alpha$-Mannan, a major component of fungal cell wall, induced donor T-cell polarization toward Th17, leading to exacerbated Th17pulmonary aGVHD in mice.

Some studies have also explored the role of cytokines implicated in Th17 cell differentiation. Therefore, inhibition of the IL-6 signaling pathway that drives Th17 cell differentiation by a way of antibody-mediated blockade of the IL-6 receptor markedly reduces pathologic damage attributable to GVHD. ${ }^{66}$ This effect is accompanied by a significant reduction of Th1 and Th17 cells infiltrating aGVHD target tissues and a significant increase of Treg. ${ }^{66}$ Similarly, Tawara et al. ${ }^{67}$ reported that transplantation of $I L-6-/$ - donor T cells or total inhibition of IL-6 with anti-IL-6 receptor monoclonal antibody lead to a marked decrease in aGVHD severity and prolonged survival. However, they failed to demonstrate a role of donor $\mathrm{T}$ cells in this effect. ${ }^{67}$ Other authors focused on IL-23, a cytokine that stabilizes Th17 cell phenotype $^{31}$ and expands their pathogenicity. ${ }^{27,30,32}$ Das et al. ${ }^{68}$ have shown that donor antigen-presenting cells-derived IL-23 drive gastrointestinal aGVHD. The proinflammatory effect of IL-23 was reported to be dependent upon donor-derived secretion of IFN $\gamma$ and not IL-17, despite IL-17 being significantly decreased in $I L-23-/$ - compared with wild-type donors. ${ }^{68}$ Furthermore, they have shown that under IL-23 blockade, the graft-vs.-leukemia effect was preserved. ${ }^{69}$ Thompson et al..$^{70}$ have confirmed that absence of IL-23 in donor grafts reduced the severity of aGVHD and was associated with a decrease of IL17. Th17 cells produce IL-21, involved in their differentiation, ${ }^{20,29}$ promoting, therefore, their self-maintenance. ${ }^{20}$ Transplantation with $I L-21 R-/-$ donor $\mathrm{T}$ cells resulted in less severe aGVHD, while sparing the graft-vs.leukemia effect. ${ }^{71-74}$ Furthermore, IL-21 blockade using a monoclonal antibody also decreased aGVHD. ${ }^{75}$ In these studies, the protective effect of IL-21 signaling pathway blockade on aGVHD was associated with an expansion of Tregs, and no effect was observed on the IL-17 axis. ${ }^{74,75}$ In a xenogeneic GVHD model, IL-21 blockade also significantly reduced aGVHD; ${ }^{76}$ nevertheless, this reduction was associated with an increase in Tregs and a decrease of IL-17-producing cells. ${ }^{76}$

Several studies have explored the contribution of another Th17-related cytokine, IL-22, in aGVHD pathophysiology. IL-22 is structurally related to the IL-10 family, secreted by Th17 cells, but also by others $\alpha \beta$ T cells (Th1, Th22, and CD $8+\alpha \beta$ T cells), $\gamma \delta$ T cells, natural killer T cells, and innate lymphoid cells. ${ }^{77}$ IL-22 has been reported to exert both protective and inflammatory functions, most likely depending on the cytokine microenvironment and the tissue and/or the cell type involved. ${ }^{78}$ Thus, while IL-22 has been shown to be protective in inflammatory bowel disease, ${ }^{79}$ it is pathogenic in psoriasis ${ }^{80}$ and rheumatoid arthritis. ${ }^{81}$ In aGVHD, we have recently reported that IL-22 deficiency in donor $T$ cells can decrease the severity of aGVHD while sparing the graft-vs.leukemia effect. ${ }^{82}$ Furthermore, weekly administration of IL-22, starting on day 0 , aggravates aGVHD in animal models. ${ }^{83}$ In contrast, Hanash et al. ${ }^{84}$ showed that IL-22 produced by recipient innate lymphoid cell decreased aGVHD tissue damage by protecting intestinal stem cells. Therefore, according to the cell source (donor or patient), IL-22 may have an either protective or inflammatory effect in aGVHD. The IL-22 axis remains to be further explored to decipher its exact role in aGVHD.

Overall, results from aGVHD mouse models, suggest that Th17 cells may have a role in aGVHD pathophysiology.

\section{Studies in allo-SCT patients}

The role of Th17 cells has also been investigated in human aGVHD pathophysiology. Three studies evaluated the relation between the presence of the single-nucleotide polymorphism rs11209026 (1142G $>A)$ in $I L-23 R$ and aGVHD. ${ }^{85-87}$ In two studies, ${ }^{85,86}$ there was a significant reduction of aGVHD incidence in patients who were transplanted from a donor with the $I L-23 R$ single-nucleotide polymorphism, while there was no effect when it was in the recipient, and the third study fail to identify any effect of the polymorphism. ${ }^{87}$ In healthy donors, the presence of the $I L-23 r$ single-nucleotide polymorphism promotes the expression of soluble IL-23R ${ }^{88}$ and, consequently, diminished IL-23 signaling, leading to a decreased IL-23-dependent IL-17 and IL-22 production and STAT3 phosphorylation. ${ }^{89,90}$ These data suggest that protective effects of the $I L-23 R$ polymorphism on aGVHD are mediated through selective attenuation of IL-23 induced-Th17 effector function.

Dander et al. ${ }^{91}$ and Liu et al. ${ }^{92}$ have reported that Th17 cells and IL-17 serum level were significantly increased in the blood of patients at aGVHD onset, compared with allo-SCT patients without aGVHD. Furthermore, in both studies, the increased number of circulating Th17 cells was accompanied by a decrease in circulating Tregs. ${ }^{91,92}$

Early studies failed to identify Th17 cells infiltrating aGVHD target tissues. Thus, Broady et al. ${ }^{93}$ reported that only Th1 and not Th17 cells infiltrate the skin of patients with cutaneous aGVHD. 
Similarly, Ratajczak et al. ${ }^{94}$ did not find Th17 cells in skin and gut biopsies of patients with cutaneous or gastrointestinal aGVHD. Identification was based on detection of IL-17 + cells directly by immunohistochemistry in patients' biopsies in both studies, ${ }^{93,94}$ or by flow cytometry after in vitro culture of dermal cells in the study by Broady et al. ${ }^{93}$ However, Th17 cells could convert into IFN $\gamma$-producing Th1-like cells. ${ }^{44,45}$ Given Th17 cells plasticity, IL-17 is probably not the most reliable marker. Therefore, using CD161 and CCR6, two surface marker, of Th17 cells ${ }^{45,95,96}$ and ROR $\gamma$ t, the key transcription factor that orchestrate Th17 cell differentiation, ${ }^{14}$ we have shown that the number of Th17 was significantly increased in the intestinal mucosa and the skin of patients with gastrointestinal or cutaneous aGVHD, compared with allo-SCT patients who did not developed aGVHD. ${ }^{97,98}$ Similarly, using the same two markers, van der Waart et al. ${ }^{99}$ reported that Th17 cells infiltrate aGVHD-affected tissues (intestinal mucosa and skin) while being decreased in the peripheral blood during aGVHD. Recent data have shown that circulating Th17 cells may be increased early after allo-SCT in patients who will develop aGVHD. Thus, Lee et al. ${ }^{100}$ showed that a high ratio of $\mathrm{CD} 4+$ $\mathrm{CD} 161+$ to $\mathrm{CD} 8+\mathrm{CD} 161+$, and an increased level of serum IL-17 at engraftment were associated with subsequent development of aGVHD, and that those CD4 + CD161 + cells expressed high levels of ROR $\gamma$ t. Similarly, Betts et al. ${ }^{101}$ reported that at day 21 after allo-SCT, pSTAT3, a transcription factor that directly drives the transcription of Th17 lineage-specific genes, ${ }^{15}$ was significantly increased in CD4 $+\mathrm{T}$ cells among patients who will subsequently develop aGVHD. Furthermore they confirmed that the number of $\mathrm{CD} 3+$ ROR $\gamma t+$ Th17 cells was significantly increased in aGVHD target tissues. ${ }^{101}$ Recently, a novel CD146+CCR5 + T-cell population was identified, this population was significantly increased at gastrointestinal aGVHD onset, and proven to be Th17-related ( $\mathrm{Li} \mathrm{W}$, Liu L, Gomez A, Zhang Q, Zhang J, Ramadan A et al. unpublished data). Moreover, at

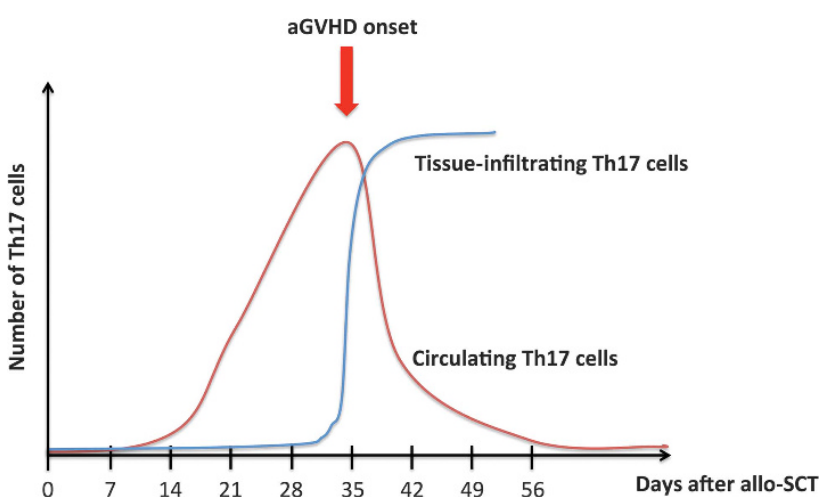

Figure 1 Kinetic of Th17 cells after allogeneic stem cell transplantation in patients who develop acute graft-vs.-host disease. aGVHD, acute graft-vs.-host disease; allo-SCT, allogeneic stem cell transplantation.

day 19 post allo-SCT, those cells were significantly increased before aGVHD onset in patients who subsequently developed gastrointestinal aGVHD, suggesting that this CD146+CCR5 + T-cell population could be used as an early biomarker of intestinal aGVHD. Finally, Reinhardt et al. ${ }^{102}$ demonstrated that peripheral monocytes isolated from patients with skin and/or gastrointestinal aGVHD induce significantly increased level of Th17 cell compared with patients without aGVHD, highlighting that activated monocytes could drive peripheral Th17 cells in aGVHD.

The role of the Th17-related cytokine, IL-22, as in murine models, seems to be dependent upon the cell source. Recently, Munneke et al. have shown that appearance of donor origin natural cytotoxicity receptor-positive innate lymphoid cell, an important innate source of IL-22, correlated with a decreased incidence of aGVHD. ${ }^{103}$

Overall, these results suggest that circulating Th17 cells are increased early after allo-SCT in patients who develop aGVHD, and that, at its onset, circulating Th17 decrease in the peripheral because they migrate into the aGVHD target tissue, where they trigger its damage (Figure 1).

\section{Th17 CELLS: A NEW TARGET FOR aGVHD PREVENTION AND TREATMENT}

So far, the most widely used immunosuppressive drugs for aGVHD prevention and therapy increase the infection risk, and present side effects other than those related to their immunosuppressive properties. Thus there is a need for more specific and less toxic approaches. Given growing evidence suggesting that Th17 cells have a role in aGVHD, they represent a promising therapeutic target toward which to design new approaches for aGVHD treatment, but also for prevention or pre-emptive therapy, since circulating Th17 are increased before aGVHD onset

\section{(Table 1, Figure 2).}

Several monoclonal antibodies, antiIL-17A (ixekizumab, secukinumab) or anti-Il-17R (brodalumab), have proven to be effective in psoriasis, an IL-17related autoinflammatory skin diseases. ${ }^{104-106}$ However, these results do not guarantee the effectiveness of these monoclonal antibodies in aGVHD. In fact, brodalumab and secukinumab were ineffective for Crohn's disease treatment, ${ }^{107,108}$ while IL-17 was reported to drive Crohn's disease. ${ }^{108}$ For the IL-22/IL-22R axis, further exploration to delineate its inflammatory vs. protective effects in aGVHD is indispensable, before considering targeting it.

Given IL- $1 \beta$ and IL- 6 drive Th17 cell differentiation, therapy targeting IL- $1 \beta$ and IL- 6 has been evaluated in clinical trials. Blocking IL- $1 \beta$ using recombinant human IL-1R antagonist was proven to be ineffective for aGVHD prevention, ${ }^{109}$ while tocilizumab, an anti-IL-6 receptor monoclonal antibody, has shown promising results for aGVHD prophylaxis in a phase $1 / 2$ trial, ${ }^{110}$ and several phase 2 trial are ongoing. As IL-23 expands the pathogenicity of Th17 cells,,$^{27,30,32}$ it 
Table 1 Potential therapeutic agents targeting the Th17 axis for acute GVHD treatment

\begin{tabular}{|c|c|c|c|c|}
\hline Target & Drug & Companies & Clinical stage in aGVHD & Clinical trial identifier and publication \\
\hline IL-6R & Tocilizumab & Roche & $\begin{array}{l}\text { Phase } 1 / 2 \text { completed }^{110} \\
\text { Phase } 1 / 2 \text { ongoing } \\
\text { Phase } 2 \text { ongoing } \\
\text { Phase } 2 \text { ongoing }\end{array}$ & $\begin{array}{l}\text { ACTRN12612000726853 } \\
\text { NCT01475162 } \\
\text { NCT01757197 } \\
\text { NCT02206035 }\end{array}$ \\
\hline IL-23-p40 & Ustekinumab & Janssen & Phase 2 ongoing & NCT01713400 \\
\hline STAT3 & $\begin{array}{l}\text { Ruxolitinib } \\
\text { Tofacitinib }\end{array}$ & $\begin{array}{l}\text { Novartis } \\
\text { Pfizer }\end{array}$ & $\begin{array}{l}\text { Retrospective study }{ }^{116} \\
\text { Not evaluated in GVHD }\end{array}$ & NA \\
\hline IL-17A & $\begin{array}{l}\text { Ixekizumab } \\
\text { Secukinumab } \\
\text { CNTO } 6785 \\
\text { SCH } 900117 \\
\text { CJM112 }\end{array}$ & $\begin{array}{l}\text { Eli Lilly } \\
\text { Novartis } \\
\text { Janssen } \\
\text { Merk } \\
\text { Novartis }\end{array}$ & Not evaluated in GVHD & NA \\
\hline IL-17A and IL-17F & $\begin{array}{l}\text { Bimekizumab } \\
\text { ALX-0761 }\end{array}$ & $\begin{array}{l}\text { UCB } \\
\text { Merk } \\
\text { Serono/Ablynx }\end{array}$ & & NA \\
\hline IL-17R & Brodalumab & Amgen & Not evaluated in GVHD & NA \\
\hline $\mathrm{IL}-21$ & $\begin{array}{l}\text { NNC0114-0005 } \\
\text { NNC0114-0006 } \\
\text { ATR-107 }\end{array}$ & $\begin{array}{l}\text { Novo Nordisk } \\
\text { Novo Nordisk } \\
\text { Pfizer }\end{array}$ & Not evaluated in GVHD & NA \\
\hline
\end{tabular}

Abbreviations: aGVHD, acute graft-vs.-host disease; IL-6R, interleukin-6 receptor; NA, not available; Th17, T helper 17.

appears to be also a promising therapeutic target. Therefore, ustekinumab, a monoclonal antibody that binds the p40 subunit shared by IL-12 and IL-23, approved for psoriasis and effective in Crohn's disease, ${ }^{111}$ has demonstrated efficacy in one case report of glucocorticoid-refractory aGVHD. ${ }^{112}$ Ustekinumab is currently evaluated for aGVHD prevention in combination with tacrolimus and sirolimus (NCT01713400). Several monoclonal antibodies targeting the IL-23-p19 are also being evaluated in phase 1,2, or 3 trials for psoriasis and rheumatoid arthritis; raising the possibility to evaluate them for aGVHD treatment. Finally, several monoclonal antibodies targeting IL-21, a cytokine that promotes Th17 cell self-maintenance, ${ }^{20}$ are under development for rheumatoid arthritis, Crohn's disease and systemic lupus erythematosus, ${ }^{113}$ and represent a potential therapeutic strategy for aGVHD.
Some inhibitory molecules directly target Th17 cells. Thus, pharmacological inhibition with KD025 of Rho-associated kinase 2 significantly diminished STAT3 phosphorylation and binding to $I L-17$ and $I L-21$ promoters in mouse models. ${ }^{114}$ Also, the Janus family kinase (JAK) inhibitors, Tofacitinib, a JAK1/3 inhibitor and Ruxolitinib, a JAK1/2 inhibitor, block STAT3 phosphorylation resulting in the suppression of Th17 cell differentiation. ${ }^{115}$ Tofacitinib and Ruxolitinib have proven to be effective for psoriasis treatment in human in phase 3 and 2 trials, respectively. Zeiser et al. recently reported a retrospective study evaluating Ruxolitinib for corticosteroid refractory aGVHD in 54 patients. ${ }^{16}$ The overall response rate was $81.5 \%$, including 25 complete responses (46.3\%), highlighting the therapeutic potential of JAK inhibitors for the treatment of aGVHD. ${ }^{116}$ Prospective studies evaluating Ruxolitinib and Tofacitinib for
aGVHD prevention or treatment are expected. Finally, several additional molecules that could block the Th17 pathway are at a preclinical development stage, such as inhibitors of ROR $\gamma \mathrm{t}^{117}$ or retinoid acid receptor $\alpha$ agonist. ${ }^{118}$

\section{CONCLUSION AND PERSPECTIVE}

Significant achievements have been made in the understanding of Th17 cells pathophysiology. Recent data showing an increased Th17 cell population during or preceding aGVHD are of particular interest, highlighting that these cells could be targeted not only for aGVHD treatment, but also earlier for its prevention. The increased number of monoclonal antibodies and inhibitory molecules targeting the Th17 pathway hold promise for identification of more effective treatment for aGVHD prevention and treatment. Efforts must be pursued to evaluate those forms of treatment in aGVHD. 


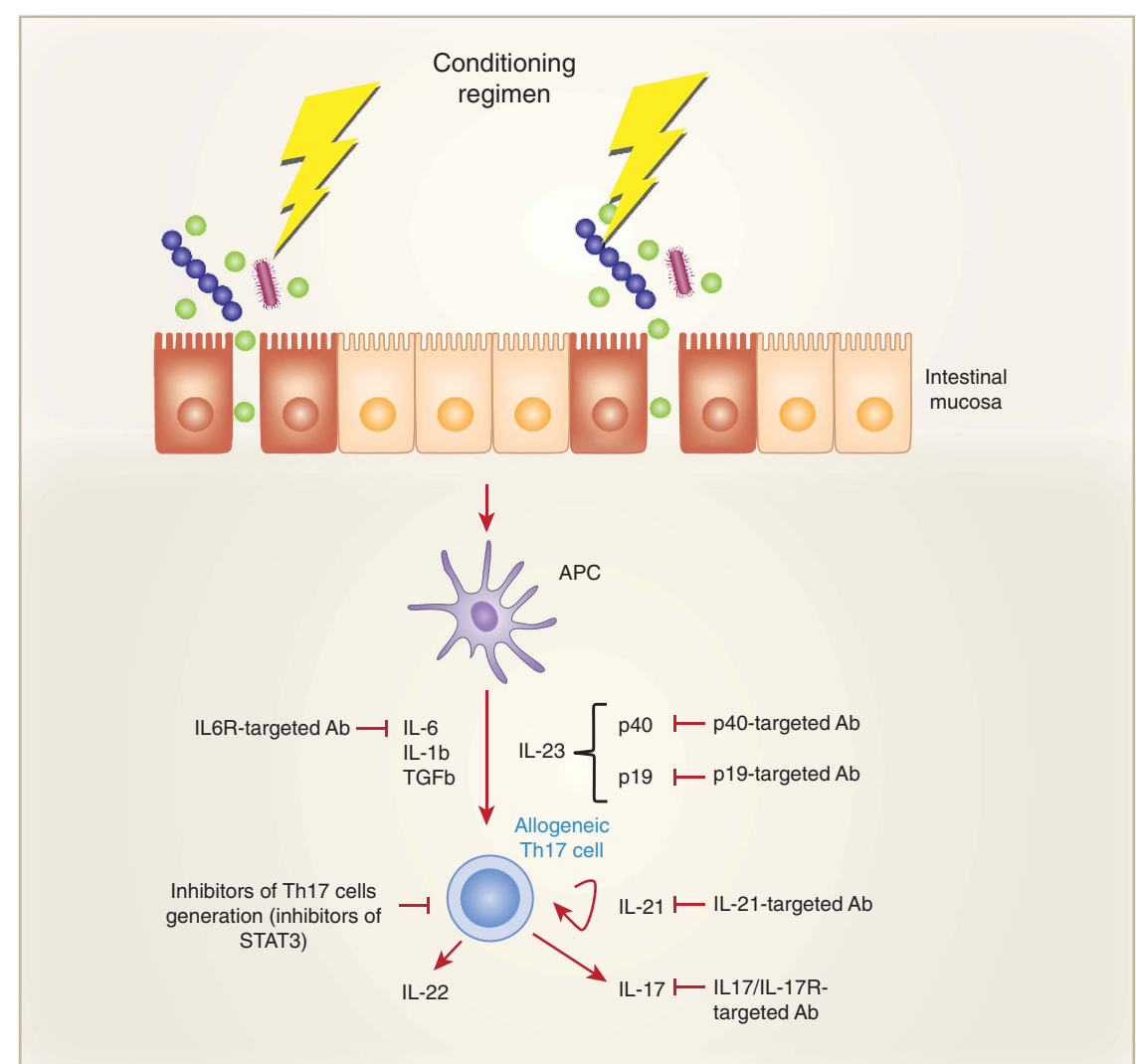

Figure 2 Potential therapeutic targets of the Th17 pathway implicated in acute graft-vs.-host disease, example of the intestinal acute graft-vs.-host disease. The conditioning regimen leads to host intestinal tissue damage and activation of host antigen-presenting cells that will drive Th17 differentiation through IL-6, IL-1 $\beta$, TGF $\beta$, and IL-23. Various therapeutic tools are available to target Th17 pathway. Cytokines driving Th17 cells differentiation could be target by monoclonal antibodies: tocilizumab target IL-6R ustekinumab target the $\mathrm{p} 40$ subunit share by IL-12 and IL-23 and the p19 subunit of IL-23 is targeted by Tildrakizumab, Guselkumab, AMG 139, BI 655066, and LY3074828. Th17 differentiation could also be target by inhibitors of Th17 generation, such as the JAK inhibitors Tofacitinib and Ruxolitinib that block STAT3 phosphorylation. Several monoclonal antibodies could target Th17-related cytokines: IL-17A (Ixekizumab, Secukinumab, CNTO 6785, SCH 900117 and CJM112), IL-17A and IL-17F (Bimekizumab and ALX-0761), and IL-21 (NNC0114-0005, NNC01140006 and ATR-107). Alternatively, IL-17R could be targeted by the monoclonal antibody Brodalumab. Finally, given the contradictory data regarding the inflammatory vs. protective effect of IL-22 in aGVHD, no therapeutic strategy related to IL-22 could be proposed at moment. Ab, monoclonal antibody; aGVHD, acute graft-vs.-host disease; APC, antigen-presenting cell; IL-6R, interleukin-6 receptor; TGF $\beta$, transforming growth factor- $\beta$; Th17, T helper 17.

\section{ACKNOWLEDGMENTS}

FM was supported by educational grants from the "Association for Training, Education and Research in Hematology, Immunology and Transplantation" (ATERHIT). This work was carried out in the context of the IHU-Cesti project, which received French government financial support managed by the National Research Agency, via the "Investment Into The Future" program ANR-10-IBHU-005. The IHU-Cesti project is also supported by Nantes Metropole and the Pays de la Loire Region. We also thank the "Association pour la Recherche sur le Cancer (ARC)", the "Fondation de France", the "Fondation contre la Leucémie", the "Agence de Biomédecine", the "Association Cent pour Sang la Vie", the "Association Laurette Fugain", the "IRGHET" and the "Ligue Contre le Cancer" (Comités Grand-Ouest), for their generous and continuous support to our clinical and basic research work. Our transplant programs are supported by several grants from the French National Cancer Institute. We are grateful to Professor Junia V. Melo (University of Adelaide, Australia, and Imperial College, London) for medical editing of this manuscript.

\section{AUTHOR CONTRIBUTIONS}

F.M. designed the manuscript, analyzed the literature, wrote and commented on the manuscript. B.G. analyzed the literature, assisted in writing, and commented on the manuscript. B.L. analyzed the literature, assisted in writing, and commented on the manuscript. M.M. designed the manuscript, analyzed the literature, wrote and commented on the manuscript. All authors approved submission of the manuscript for publication purposes.
DISCLOSURE

The authors declare no conflict of interest.

c) 2016 Society for Mucosal Immunology

\section{REFERENCES}

1. Gooley, T.A. et al. Reduced mortality after allogeneic hematopoietic-cell transplantation. N. Engl. J. Med. 363, 2091-2101 (2010).

2. Malard, F. et al. Continuous reduced nonrelapse mortality after allogeneic hematopoietic stem cell transplantation: a single-institution's three decade experience. Biol. Blood Marrow Transplant. 20, 1217-1223 (2014).

3. Paczesny, S. Discovery and validation of graft-versus-host disease biomarkers. Blood 121, 585-594 (2013).

4. Paczesny, S., Levine, J.E., Braun, T.M. \& Ferrara, J.L. Plasma biomarkers in graftversus-host disease: a new era? Biol. Blood Marrow Transplant. 15 (1 Suppl), 33-38 (2009).

5. Malard, F. \& Mohty, M. New insight for the diagnosis of gastrointestinal acute graftversus-host disease. Mediators Inflamm. 2014, 701013 (2014).

6. Coron, E. et al. Early detection of acute graftversus-host disease by wireless capsule endoscopy and probe-based confocal laser endomicroscopy: results of a pilot study. United European Gastroenterol. J. 2, 206-215 (2014).

7. Bodet-Milin, C. et al. F-FDG PET/CT for the assessment of gastrointestinal GVHD: results of a pilot study. Bone Marrow Transplant. 49, 131-137 (2013).

8. Mohty, M. \& Gaugler, B. Inflammatory cytokines and dendritic cells in acute graftversus-host disease after allogeneic stem cell transplantation. Cytokine Growth Factor Rev. 19, 53-63 (2008).

9. Ferrara, J.L., Levine, J.E., Reddy, P. \& Holler, E. Graft-versus-host disease. Lancet 373 , 1550-1561 (2009)

10. Krenger, W. \& Ferrara, J.L. Graft-versus-host disease and the Th1/Th2 paradigm. Immunol. Res. 15, 50-73 (1996).

11. Holler, E. et al. Modulation of acute graftversus-host-disease after allogeneic bone marrow transplantation by tumor necrosis factor alpha (TNF alpha) release in the course of pretransplant conditioning: role of conditioning regimens and prophylactic application of a monoclonal antibody neutralizing human TNF alpha (MAK 195F). Blood 86, 890-899 (1995).

12. Harrington, L.E. et al. Interleukin 17-producing CD4 + effector T cells develop via a lineage distinct from the $T$ helper type 1 and 2 lineages. Nat. Immunol. 6, 1123-1132 (2005).

13. Park, H. et al. A distinct lineage of CD4 T cells regulates tissue inflammation by producing interleukin 17. Nat. Immunol. 6, 1133-1141 (2005).

14. Ivanov, II et al. The orphan nuclear receptor RORgammat directs the differentiation 
program of proinflammatory IL-17 + Thelper cells. Cell 126, 1121-1133 (2006).

15. Durant, L. et al. Diverse targets of the transcription factor STAT3 contribute to $T$ cell pathogenicity and homeostasis. Immunity 32, 605-615 (2010).

16. Yang, X.O. et al. STAT3 regulates cytokinemediated generation of inflammatory helper T cells. J. Biol. Chem. 282, 9358-9363 (2007).

17. Bettelli, E. et al. Reciprocal developmental pathways for the generation of pathogenic effector TH17 and regulatory T cells. Nature 441, 235-238 (2006).

18. Chung, Y. et al. Critical regulation of early Th17 cell differentiation by interleukin-1 signaling. Immunity 30, 576-587 (2009).

19. Wei, L., Laurence, A., Elias, K.M. \& O'Shea, J.J. IL-21 is produced by Th17 cells and drives IL-17 production in a STAT3dependent manner. J. Biol. Chem. 282, 34605-34610 (2007).

20. Zhou, L. et al. IL-6 programs $T(H)-17$ cell differentiation by promoting sequential engagement of the IL-21 and IL-23 pathways. Nat. Immunol. 8, 967-974 (2007).

21. Veldhoen, M., Hocking, R.J., Flavell, R.A. \& Stockinger, B. Signals mediated by transforming growth factor-beta initiate autoimmune encephalomyelitis, but chronic inflammation is needed to sustain disease. Nat. Immunol. 7, 1151-1156 (2006).

22. Gutcher, I., Donkor, M.K., Ma, Q., Rudensky, A.Y., Flavell, R.A. \& Li, M.O. Autocrine transforming growth factor-beta1 promotes in vivo Th17 cell differentiation. Immunity 34 , 396-408 (2011).

23. Das, J. et al. Transforming growth factor beta is dispensable for the molecular orchestration of Th17 cell differentiation. J. Exp. Med. 206, 2407-2416 (2009).

24. Qin, H. et al. TGF-beta promotes Th17 cell development through inhibition of SOCS3. J. Immunol. 183, 97-105 (2009).

25. Wilson, N.J. et al. Development, cytokine profile and function of human interleukin 17producing helper T cells. Nat. Immunol. 8, 950-957 (2007).

26. Acosta-Rodriguez, E.V., Napolitani, G., Lanzavecchia, A. \& Sallusto, F. Interleukins 1 beta and 6 but not transforming growth factor-beta are essential for the differentiation of interleukin 17-producing human $\mathrm{T}$ helper cells. Nat. Immunol. 8, 942-949 (2007).

27. Ghoreschi, K. et al. Generation of pathogenic $\mathrm{T}(\mathrm{H}) 17$ cells in the absence of TGF-beta signalling. Nature 467, 967-971 (2010).

28. Volpe, E. et al. A critical function for transforming growth factor-beta, interleukin 23 and proinflammatory cytokines in driving and modulating human $\mathrm{T}(\mathrm{H})-17$ responses. Nat. Immunol. 9, 650-657 (2008).

29. Manel, N., Unutmaz, D. \& Littman, D.R. The differentiation of human $T(H)-17$ cells requires transforming growth factor-beta and induction of the nuclear receptor RORgammat. Nat. Immunol. 9, 641-649 (2008).

30. McGeachy, M.J. et al. TGF-beta and IL-6 drive the production of IL-17 and IL-10 by $T$ cells and restrain $T(H)-17$ cell-mediated pathology. Nat. Immunol. 8, 1390-1397 (2007).

31. McGeachy, M.J. et al. The interleukin 23 receptor is essential for the terminal differentiation of interleukin 17-producing effector $\mathrm{T}$ helper cells in vivo. Nat. Immunol. 10, 314-324 (2009).

32. Haines, C.J. et al. Autoimmune memory T helper 17 cell function and expansion are dependent on interleukin-23. Cell Rep. 3, 1378-1388 (2013).

33. Weaver, C.T., Harrington, L.E., Mangan, P.R., Gavrieli, M. \& Murphy, K.M. Th17: an effector CD4 $T$ cell lineage with regulatory $T$ cell ties. Immunity 24, 677-688 (2006).

34. Mucida, D. et al. Reciprocal $\mathrm{TH} 17$ and regulatory $T$ cell differentiation mediated by retinoic acid. Science 317, 256-260 (2007).

35. Coombes, J.L. et al. A functionally specialized population of mucosal CD103 + DCs induces Foxp3 + regulatory Tcells via a TGFbeta and retinoic acid-dependent mechanism. J. Exp. Med. 204, 1757-1764 (2007).

36. Benson, M.J., Pino-Lagos, K., Rosemblatt, M. \& Noelle, R.J. All-trans retinoic acid mediates enhanced Treg cell growth, differentiation, and gut homing in the face of high levels of co-stimulation. J. Exp. Med. 204, 1765-1774 (2007).

37. Sun, C.M. et al. Small intestine lamina propria dendritic cells promote de novo generation of Foxp3 T reg cells via retinoic acid. J. Exp. Med. 204, 1775-1785 (2007).

38. Yang, X.O. et al. Molecular antagonism and plasticity of regulatory and inflammatory Tcell programs. Immunity 29, 44-56 (2008).

39. Koenen, H.J., Smeets, R.L., Vink, P.M., van Rijssen, E., Boots, A.M. \& Joosten, I. Human CD25highFoxp3pos regulatory $T$ cells differentiate into IL-17-producing cells. Blood 112, 2340-2352 (2008).

40. Hovhannisyan, Z., Treatman, J., Littman, D.R. \& Mayer, L. Characterization of interleukin-17-producing regulatory $T$ cells in inflamed intestinal mucosa from patients with inflammatory bowel diseases. Gastroenterology 140, 957-965 (2011).

41. Voo, K.S. et al. Identification of IL-17-producing FOXP3 + regulatory T cells in humans. Proc. Natl Acad. Sci. USA 106, 4793-4798 (2009).

42. Presky, D.H. et al. A functional interleukin 12 receptor complex is composed of two beta-type cytokine receptor subunits. Proc. Natl Acad. Sci. USA 93, 14002-14007 (1996).

43. Rogge, L. et al. Selective expression of an interleukin-12 receptor component by human T helper 1 cells. J. Exp. Med. 185, 825-831 (1997).

44. Lexberg, M.H. et al. Th memory for interleukin-17 expression is stable in vivo. Eur. J. Immunol. 38, 2654-2664 (2008).

45. Annunziato, F. et al. Phenotypic and functional features of human Th17 cells. J. Exp. Med. 204, 1849-1861 (2007).

46. Antebi, Y.E. et al. Mapping differentiation under mixed culture conditions reveals a tunable continuum of T cell fates. PLoS Biol. 11, e1001616 (2013).
47. Peine, M. et al. Stable T-bet(+)GATA-3(+) Th1/Th2 hybrid cells arise in vivo, can develop directly from naive precursors, and limit immunopathologic inflammation. PLoS Biol. 11, e1001633 (2013).

48. Hegazy, A.N. et al. Interferons direct Th2 cell reprogramming to generate a stable GATA$3(+)$ T-bet $(+)$ cell subset with combined Th2 and Th1 cell functions. Immunity $32,116-128$ (2010).

49. Califano, D. et al. Diverting $T$ helper cell trafficking through increased plasticity attenuates autoimmune encephalomyelitis. J. Clin. Invest. 124, 174-187 (2014).

50. Korn, T., Bettelli, E., Oukka, M. \& Kuchroo, V.K. IL-17 and Th17 Cells. Annu. Rev. Immunol. 27, 485-517 (2009).

51. Ivanov, II et al. Induction of intestinal Th17 cells by segmented filamentous bacteria. Cell 139, 485-498 (2009).

52. Pepper, M. et al. Different routes of bacterial infection induce long-lived $\mathrm{TH} 1$ memory cells and short-lived TH17 cells. Nat. Immunol. 11, 83-89 (2010).

53. Chen, K. et al. Th17 cells mediate cladespecific, serotype-independent mucosal immunity. Immunity 35, 997-1009 (2011).

54. Khader, S.A., Gaffen, S.L. \& Kolls, J.K. Th17 cells at the crossroads of innate and adaptive immunity against infectious diseases at the mucosa. Mucosal Immunol. 2, 403-411 (2009).

55. Liang, S.C. et al. Interleukin (IL)-22 and IL-17 are coexpressed by Th17 cells and cooperatively enhance expression of antimicrobial peptides. J. Exp. Med. 203, 2271-2279 (2006).

56. Lu, S.X. et al. STAT-3 and ERK $1 / 2$ phosphorylation are critical for T-cell alloactivation and graft-versus-host disease. Blood 112, 5254-5258 (2008).

57. Carlson, M.J. et al. In vitro-differentiated TH17 cells mediate lethal acute graft-versus-host disease with severe cutaneous and pulmonary pathologic manifestations. Blood 113, 1365-1374 (2009).

58. Iclozan, C. et al. Thelper17 cells are sufficient but not necessary to induce acute graftversus-host disease. Biol. Blood Marrow Transplant. 16, 170-178 (2010).

59. Kappel, L.W. et al. IL-17 contributes to CD4mediated graft-versus-host disease. Blood 113, 945-952 (2009).

60. Yi, T. et al. Absence of donor Th17 leads to augmented Th1 differentiation and exacerbated acute graft-versus-host disease. Blood 112, 2101-2110 (2008).

61. Gartlan, K.H. et al. Tc17 cells are a proinflammatory, plastic lineage of pathogenic CD8 + T-cells that induce GVHD without anti-leukemic effects. Blood 126, 1609-1620 (2015).

62. Yi, T. et al. Reciprocal differentiation and tissue-specific pathogenesis of Th1, Th2, and Th17 cells in graft-versus-host disease. Blood 114, 3101-3112 (2009).

63. Fulton, L.M. et al. Attenuation of acute graft-versus-host disease in the absence of the transcription factor RORgammat. J. Immunol. 189, 1765-1772 (2012). 
64. Hill, G.R. et al. Stem cell mobilization with G-CSF induces type 17 differentiation and promotes scleroderma. Blood 116, 819-828 (2010).

65. Uryu, $\mathrm{H}$. et al. alpha-Mannan induces Th17-mediated pulmonary graft-versus-host disease in mice. Blood 125, 3014-3023 (2015).

66. Chen, $X$. et al. Blockade of interleukin- 6 signaling augments regulatory T-cell reconstitution and attenuates the severity of graftversus-host disease. Blood 114, 891-900 (2009).

67. Tawara, I. et al. Interleukin-6 modulates graftversus-host responses after experimental allogeneic bone marrow transplantation. Clin. Cancer Res. 17, 77-88 (2011).

68. Das, R., Chen, X., Komorowski, R., Hessner, M.J. \& Drobyski, W.R. Interleukin23 secretion by donor antigen-presenting cells is critical for organ-specific pathology in graft-versus-host disease. Blood 113, 2352-2362 (2009).

69. Das, R. et al. Blockade of interleukin-23 signaling results in targeted protection of the colon and allows for separation of graft-versus-host and graft-versus-leukemia responses. Blood 115, 5249-5258 (2010).

70. Thompson, J.S., Chu, Y., Glass, J.F. \& Brown, S.A. Absence of IL-23p19 in donor allogeneic cells reduces mortality from acute GVHD. Bone Marrow Transplant. 45, 712-722 (2010).

71. Meguro, A. et al. IL-21 is critical for GVHD in a mouse model. Bone Marrow Transplant. 45, 723-729 (2010).

72. Oh, I. et al. Altered effector CD4 $+\mathrm{T}$ cell function in IL-21R-/- CD4+ T cellmediated graft-versus-host disease. J. Immunol. 185, 1920-1926 (2010).

73. Meguro, A. et al. Lack of IL-21 signal attenuates graft-versus-leukemia effect in the absence of CD8 T-cells. Bone Marrow Transplant. 46, 1557-1565 (2011).

74. Hanash, A.M. et al. Abrogation of donor T-cell IL-21 signaling leads to tissue-specific modulation of immunity and separation of GVHD from GVL. Blood 118, 446-455 (2011).

75. Bucher, C. et al. IL-21 blockade reduces graft-versus-host disease mortality by supporting inducible Tregulatory cell generation. Blood 114, 5375-5384 (2009).

76. Hippen, K.L. et al. Blocking IL-21 signaling ameliorates xenogeneic GVHD induced by human lymphocytes. Blood 119, 619-628 (2012).

77. Dudakov, J.A., Hanash, A.M. \& van den Brink, M.R. Interleukin-22: immunobiology and pathology. Annu. Rev. Immunol. 33, 747-785 (2015)

78. Zenewicz, L.A. \& Flavell, R.A. Recent advances in IL-22 biology. Int. Immunol. 23, 159-163 (2011).

79. Zenewicz, L.A. et al. Innate and adaptive interleukin-22 protects mice from inflammatory bowel disease. Immunity 29, 947-957 (2008)

80. Wolk, K. et al. IL-22 increases the innate immunity of tissues. Immunity 21, 241-254 (2004).
81. Geboes, L. et al. Proinflammatory role of the Th17 cytokine interleukin-22 in collageninduced arthritis in C57BL/6 mice. Arthritis Rheum. 60, 390-395 (2009).

82. Couturier, M. et al. IL-22 deficiency in donor $T$ cells attenuates murine acute graftversus-host disease mortality while sparing the graft-versus-leukemia effect. Leukemia 27, 1527-1537 (2013).

83. Zhao, K. et al. Interleukin-22 aggravates murine acute graft-versus-host disease by expanding effector $T$ cell and reducing regulatory T cell. J. Interferon Cytokine Res. 34, 707-715 (2014).

84. Hanash, A.M. et al. Interleukin-22 protects intestinal stem cells from immune-mediated tissue damage and regulates sensitivity to graft versus host disease. Immunity 37 339-350 (2012).

85. Elmaagacli, A.H., Koldehoff, M., Landt, O. \& Beelen, D.W. Relation of an interleukin-23 receptor gene polymorphism to graft-versushost disease after hematopoietic-cell transplantation. Bone Marrow Transplant. 41, 821-826 (2008).

86. Gruhn, B. et al. Polymorphism of interleukin23 receptor gene but not of NOD2/CARD15 is associated with graft-versus-host disease after hematopoietic stem cell transplantation in children. Biol. Blood Marrow Transplant. 15, 1571-1577 (2009).

87. Nguyen, $Y$. et al. Insufficient evidence for association of NOD2/CARD15 or other inflammatory bowel disease-associated markers on GVHD incidence or other adverse outcomes in T-replete, unrelated donor transplantation. Blood 115, 3625-3631 (2010).

88. Yu, R.Y., Brazaitis, J. \& Gallagher, G. The human IL-23 receptor rs11209026 A allele promotes the expression of a soluble IL-23Rencoding mRNA species. J. Immunol. 194, 1062-1068 (2015).

89. Di Meglio, P. et al. The IL23R R381Q gene variant protects against immune-mediated diseases by impairing IL-23-induced Th17 effector response in humans. PLOS ONE 6, e17160 (2011).

90. Sarin, R., Wu, X. \& Abraham, C. Inflammatory disease protective R381Q IL23 receptor polymorphism results in decreased primary CD4 + and CD8 + human T-cell functional responses. Proc. Natl Acad. Sci. USA 108, 9560-9565 (2011).

91. Dander, E. et al. Interleukin-17-producing T-helper cells as new potential player mediating graft-versus-host disease in patients undergoing allogeneic stem-cell transplantation. Transplantation 88, 12611272 (2009).

92. Liu, Y. et al. The expression of Th17-associated cytokines in human acute graftversus-host disease. Biol. Blood Marrow Transplant. 19, 1421-1429 (2013).

93. Broady, R. et al. Cutaneous GVHD is associated with the expansion of tissue localised Th1 and not Th17 cells. Blood 116, 5748-5751 (2010).

94. Ratajczak, P. et al. Th17/Treg ratio in human graft-versus-host disease. Blood 116, 1165-1171 (2010).
95. Acosta-Rodriguez, E.V. et al. Surface phenotype and antigenic specificity of human interleukin 17-producing $\mathrm{T}$ helper memory cells. Nat. Immunol. 8, 639-646 (2007).

96. Kleinschek, M.A. et al. Circulating and gut-resident human Th17 cells express CD161 and promote intestinal inflammation. J. Exp. Med. 206, 525-534 (2009).

97. Bossard, C. et al. Plasmacytoid dendritic cells and Th17 immune response contribution in gastrointestinal acute graft-versus-host disease. Leukemia 26, 1471-1474 (2012).

98. Malard, F. et al. Increased plasmacytoid dendritic cells and RORgammat-expressing immune effectors in cutaneous acute graft-versus-host disease. J. Leukoc. Biol. 94, 1337-1343 (2013).

99. van der Waart, A.B. et al. Decreased levels of circulating IL17-producing CD161(+) CCR6 $(+) \quad T$ cells are associated with graft-versus-host disease after allogeneic stem cell transplantation. PLOS ONE 7, e50896 (2012).

100. Lee, S.E. et al. CD161(+) Tcells as predictive markers for acute graft-versus-host disease. Biol. Blood Marrow Transplant. 21, 421-428 (2015).

101. Betts, B.C. et al. CD4 + T cell STAT3 phosphorylation precedes acute GVHD, and subsequent Th17 tissue invasion correlates with GVHD severity and therapeutic response. J. Leukoc. Biol. 97, 807-819 (2015).

102. Reinhardt, K. et al. Monocyte-induced development of Th17 cells and the release of $\mathrm{S} 100$ proteins are involved in the pathogenesis of graft-versus-host disease. J. Immunol. 193, 3355-3365 (2014).

103. Munneke, J.M. et al. Activated innate lymphoid cells are associated with a reduced susceptibility to graft-versus-host disease. Blood 124, 812-821 (2014).

104. Leonardi, C. et al. Anti-interleukin-17 monoclonal antibody ixekizumab in chronic plaque psoriasis. N. Engl. J. Med. 366, 1190-1199 (2012).

105. Langley, R.G. et al. Secukinumab in plaque psoriasis-results of two phase 3 trials. N. Engl. J. Med. 371, 326-338 (2014).

106. Papp, K.A. et al. Brodalumab, an anti-interleukin-17-receptor antibody for psoriasis. N. Engl. J. Med. 366, 1181-1189 (2012).

107. Targan, S.R. et al. A randomized, doubleblind, placebo-controlled study to evaluate the safety, tolerability, and efficacy of AMG 827 in subjects with moderate to severe Crohn's disease. Gastroenterology 143, e26 (2012).

108. Hueber, W. et al. Secukinumab, a human antiIL-17A monoclonal antibody, for moderate to severe Crohn's disease: unexpected results of a randomised, double-blind placebocontrolled trial. Gut 61, 1693-1700 (2012).

109. Antin, J.H. et al. Interleukin-1 blockade does not prevent acute graft-versus-host disease: results of a randomized, doubleblind, placebo-controlled trial of interleukin-1 receptor antagonist in allogeneic bone marrow transplantation. Blood 100, 3479-3482 (2002). 
110. Kennedy, G.A. et al. Addition of interleukin-6 inhibition with tocilizumab to standard graftversus-host disease prophylaxis after allogeneic stem-cell transplantation: a phase 1/2 trial. Lancet Oncol. 15, 1451-1459 (2014).

111. Sandborn, W.J. et al. Ustekinumab induction and maintenance therapy in refractory Crohn's disease. N. Engl. J. Med. 367, 1519-1528 (2012).

112. Pidala, J., Perez, L., Beato, F. \& Anasetti, C. Ustekinumab demonstrates activity in glucocorticoid-refractory acute GVHD. Bone Marrow Transplant. 47, 747-748 (2012).
113. Spolski, R. \& Leonard, W.J. Interleukin-21: a double-edged sword with therapeutic potential. Nat. Rev. Drug Discov. 13, 379-395 (2014).

114. Zanin-Zhorov, A. et al. A selective and potent rock 2 inhibitor (KD025) decreases human STAT3-dependent IL-21 and IL-17 production and experimental chronic graft-versus-host disease (cGVHD). Blood 124, 540-540 (2014).

115. Hsu, L. \& Armstrong, A.W. JAK inhibitors: treatment efficacy and safety profile in patients with psoriasis. J. Immunol. Res. 2014, 283617 (2014).
116. Zeiser, R. et al. Ruxolitinib in corticosteroidrefractory graft-versus-host disease after allogeneic stem cell transplantation: a multicenter survey. Leukemia 29, 2062-2068 (2015).

117. Huh, J.R. \& Littman, D.R. Small molecule inhibitors of RORgammat: targeting Th17 cells and other applications. Eur. J. Immunol. 42, 2232-2237 (2012).

118. Nishimori, H. et al. Synthetic retinoid Am80 ameliorates chronic graft-versus-host disease by down-regulating Th1 and Th17. Blood 119, 285-295 (2012). 